\title{
Enzymatic Markers Playing a Definitive and Supportive Role in the Diagnosis of Malaria
}

\author{
Dr. Chaganti Sridevi MD ${ }^{1 *}$, Dr. UVPU Sowjanya MD², Dr. V.S. KalaiSelvi MD ${ }^{3}$
}

\author{
${ }^{1}$ Assistant Professor, Biochemistry, Sree Balaji Medical College and Hospital, Chrompet, Chennai, India \\ ${ }^{2}$ Assistant Professor, Biochemistry, Maharaja Institute of medical sciences, Nellimarla, Vizianagaram Andhra Pradesh, 535217, India \\ ${ }^{3}$ Professor, Biochemistry, Sree Balaji Medical College and Hospital, Chrompet, Chennai, 600044, India
}

DOI: 1 10.36347/sajb.2020.v08i05.004 $\quad$ | Received: 20.12.2019| Accepted: 27.12.2019| Published: 30.05 .2020

*Corresponding author: Dr. Chaganti Sridevi

Abstract

Original Research Article

Malaria is one disease which is dangerous in tropical world. Pathophysiological process involves centrilobular liver damage due to invading sporozites causing destruction of RBC. Liver and RBC's are abundant in Lactate Dehydrogenase (LDH), an intracellular enzyme, which is released into the circulation on injury of liver and destruction of RBC. Serum LDH activity is an extremely valuable enzymatic marker of acute malarial patients. Alanine Transaminase (ALT) is found largely in liver, so it serves as a marker of liver damage. RBC contain surplus of Acid Phosphatase (ACP). Similarly, Alkaline Phosphatase (ALP) serves as marker of liver damage. Samples were collected from 68 individuals and Enzymes were assayed on Autoanalyser while ACP was assayed on semi-autoanalyser by Kinetic Method. ). It was detected that enzyme ACP, AST, ALT, ALP activity rises significantly $(p<0.05)$ and increase in LDH is highly significant $(\mathrm{p}<0.001)$ in patients with vivax malaria as compared to the control subjects. It was further observed that enzyme AST, ALT, ALP activity increases significantly $(\mathrm{p}<0.05)$ and increase in ACP, LDH is highly significant $(\mathrm{p}<0.001)$ in falciparum malaria patients as compared to control subjects. The results of the present research provide information and association between hepatic and RBC biochemical derangements in vivax/falciparum malaria patients. Early treatment can be initiated based on these findings to avoid complications and to diminish mortality. These enzymatic markers also have a supportive role in knowing the extent of hemolysis and liver damage and thus the severity of the disease.

Keywords: Malaria, Liver enzymes, ACP, ALP, AST, ALT, LDH.

Copyright @ 2020: This is an open-access article distributed under the terms of the Creative Commons Attribution license which permits unrestricted use, distribution, and reproduction in any medium for non-commercial use (NonCommercial, or CC-BY-NC) provided the original author and source are credited

\section{INTRODUCTION}

Malaria is one disease which is serious in the tropical world. Around 300-500 million people are affected and have a mortality of about 1-3 million per year[1]. Malarial parasite, plasmodium vivax, and P.falciparum life cycle include pre-erythrocytic cycle taking place in the liver cell parenchyma and erythrocytic cycle in red blood cells[2]. The pathophysiological process involves centrilobular liver damage due to invading sporozoites, causing damage of RBC [3]. Liver and RBC's are abundant in Lactate Dehydrogenase ( $\mathrm{LDH})$, an intracellular enzyme, is released into the circulation on the injury of liver and destruction of RBC. Hence, serum LDH activity is an extremely valuable enzymatic marker of acute malarial patients, especially in the case where there is a lack of other diseases which increase serum LDH[4].
Alanine Transaminase (ALT) is mainly found in the liver. Hence, it serves as a marker of liver damage while Aspartate Transaminase (AST) is found in many tissues, including liver, muscle, heart, kidney, and brain. It increases when any of these tissues are injured. Therefore, it is not a highly precise sign of liver damage[5]. However, it has significant diagnostic value when combined with ALT.

Similarly, Alkaline Phosphatase (ALP) serves as a marker of liver damage. The pre-erythrocytic stage of plasmodium infection causes damage to hepatocytes membrane leading to leakage of this enzyme out of the liver cells. RBC contain a surplus of Acid Phosphatase (ACP)[6].

The infection of RBC by the malarial parasite during the phase of erythrocytic schizogony causes the enzyme ACP being released into the circulation [7]. The serum levels of this enzyme are then measured. This 
Chaganti Sridevi et al., Sch Acad J Biosci, May, 2020; 8(5): 133-136

study was conducted on both Plasmodium vivax \& falciparum positive malarial patients to establish the diagnostic value of (a) Serum LDH, ALP, ALT, AST activity, which are liver function biomarkers. (b) Serum LDH, ACP activity which are biomarkers OF RBC function.

\section{MATERIALS \& METHODS}

The study group comprised of 68 subjects of between age group 20-50 years and of both sexes. Of these, 28 were infected with vivax malaria, 10 were infected with falciparum malaria and 30 were healthy individuals as controls. Written and informed consent was obtained from all the subjects.

Patients were selected from individuals presenting at Sree Balaji medical college and hospital with a history of fever with chills \& rigor within a period of 1-8days. They were then confirmed to be positive for Plasmodium vivax/falciparum parasite by microscopic examination of thin blood slides which are Giemsa stained.
Inclusion criteria: Patients who were symptomatic with a positive diagnosis confirmed by geimsa stained slides were included. History was taken in detail and and physical examination was performed. Exclusion criteria: (1) Patients with fever but were negative for malaria parasite, (2) HIV-AIDS, (3)Hepatitis and Liver Cirrhosis, (4) Alcoholism, (6) Kidney Disorders, (7) Patients on self medication with any anti-malarial drugs prior to hospitalisation, (8) Pregnant Woman, (9) Malignancy The biochemical assay was carried out within $24 \mathrm{hrs}$ of collection after collection of blood samples.

Enzymes were assayed on autoanalyser while ACP was assayed on semi-autoanalyser by Kinetic Method. The data was analyzed using Student's t-test and $\mathrm{p}<0.001$ was considered as highly significant.

\section{RESULTS \& OBSERVATIONS}

The results obtained are tabulated as controls and malaria patients are shown in Table 1 (vivax malaria patients vs. controls) and Table 2 (falciparum malaria patients vs. controls), (*p value $<0.05$, ** p value $<0.001)$.

Table-1: P. vivax malaria patients vs. Controls (All values are expressed as Mean \pm S.D

\begin{tabular}{|c|c|c|c|}
\hline S.No & ENZYME ACTIVITY & CONTROLS(IU/L) & CASES(IU/L) \\
\hline 1 & ACID PHOSPHATASE & $2.2 \pm 0.6$ & $6.6 \pm 0.3^{*}$ \\
\hline 2 & ALKALINE PHOSPHATASE & $36.0 \pm 1.6$ & $89.8 \pm 8.8^{*}$ \\
\hline 3 & ASPARTATE TRANSAMINASE & $7.5 \pm 0.9$ & $36.0 \pm 2.5^{*}$ \\
\hline 4 & ALANINE TRANSAMINASE & $8.2 \pm 1.3$ & $36 \pm 1.5^{*}$ \\
\hline 5 & LACTATE DEHYDROGENASE & $247.1 \pm 19$ & $789.4 \pm 35^{* *}$ \\
\hline
\end{tabular}

From the data (Table 1) it was found that enzyme AST,ALT,ALP and ACP activity raises significantly $(\mathrm{p}<0.05)$ and increase in LDH is highly significant $(\mathrm{p}<0.001)$ in patients with vivax malaria as compared to the control subjects.

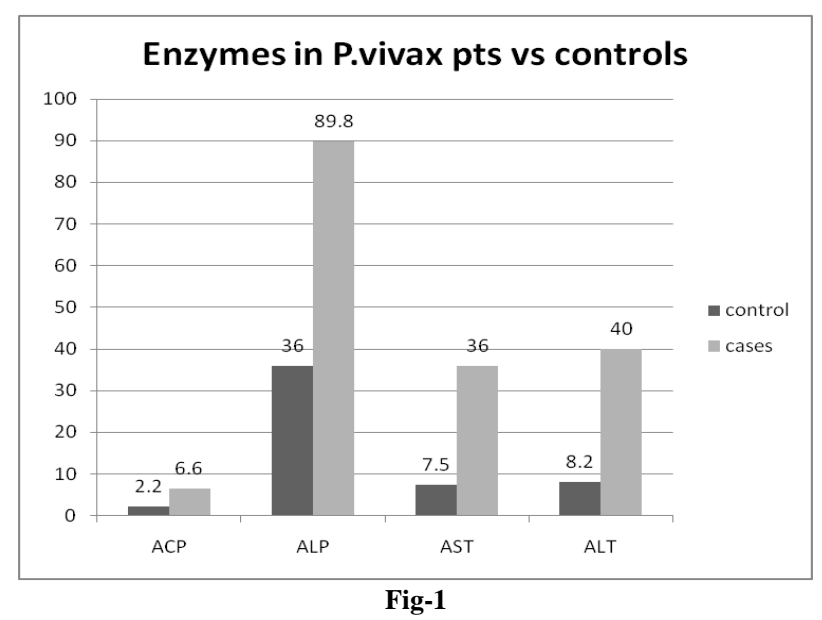




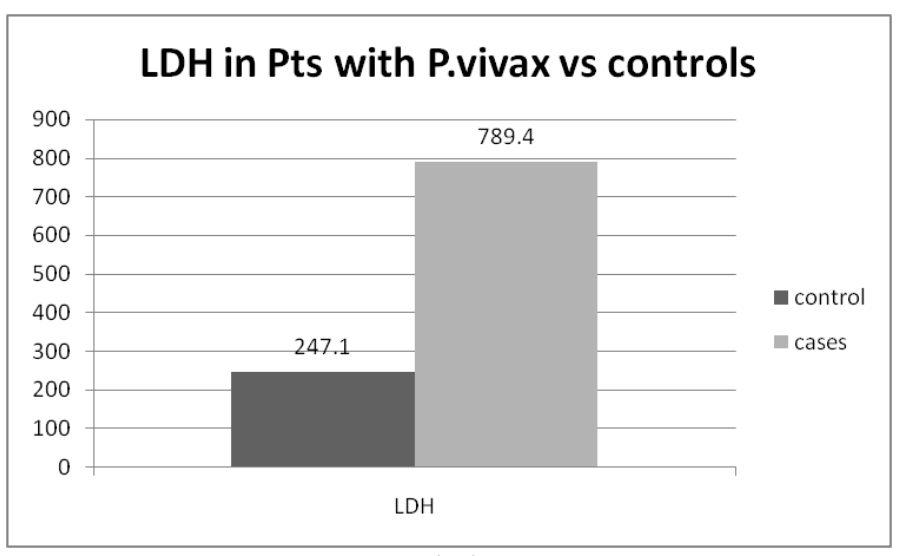

Fig-2

Table-2: P.falciparum malaria patients vs. Controls (All values are expressed as Mean \pm S.D.)

\begin{tabular}{|c|c|c|c|}
\hline S.No. & ENZYME ACTIVITY & CONTROLS(IU/L) & CASES(IU/L) \\
\hline 1 & ACID PHOSPHATASE & $2.2 \pm 0.6$ & $8.8 \pm 0.8^{* *}$ \\
\hline 2 & ALKALINE PHOSPHATASE & $36.0 \pm 1.6$ & $106.6 \pm 8.4^{*}$ \\
\hline 3 & ASPARTATE TRANSAMINASE & $7.5 \pm 0.9$ & $37.2 \pm 1.8^{*}$ \\
\hline 4 & ALANINE TRANSAMINASE & $8.2 \pm 1.3$ & $38.4 \pm 2.6^{*}$ \\
\hline 5 & LACTATE DEHYDROGENASE & $247.1 \pm 19$ & $897.6 \pm 36.3^{* *}$ \\
\hline
\end{tabular}

From the data (Table 2) it was observed that enzyme AST, ALT, ALP activity increases significantly $(p<0.05)$ and increase in ACP, LDH is highly significant $(\mathrm{p}<0.001)$ in falciparum malaria patients as compared to control subjects.

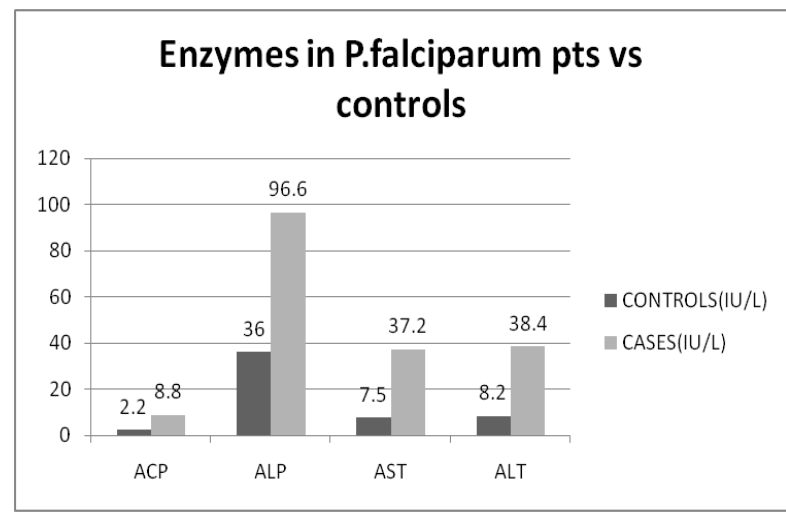

Fig-3

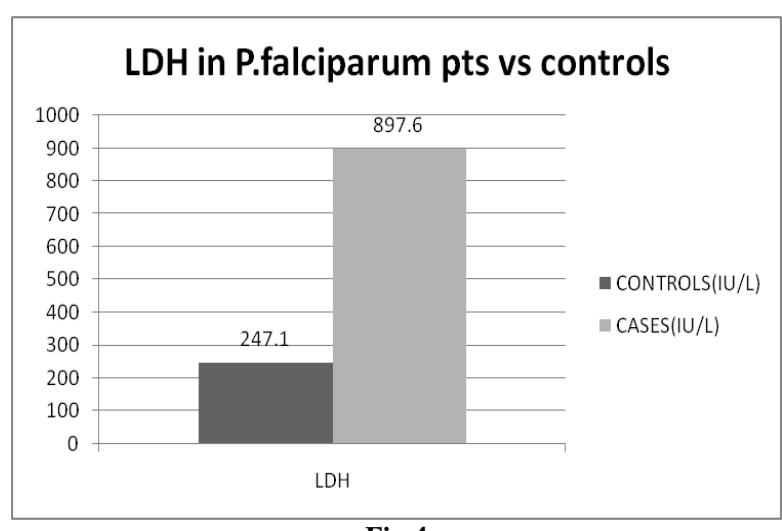

Fig-4

\section{DISCUSSION}

This study detected that the enzyme levels were raised in malaria patients when compared with controls. The detected raise in serum liver enzymes (AST, ALT, ALP) may be due to seepage from hepatic cells that were damaged by an unusual triggering of cell activation by the parasites. Previous reports [8] support this finding. Hence, in the diagnosis of malaria, there is reasoning in using these biochemical markers.

Maegraith proposed that hepatic dysfunction in malaria include an interaction between local circulatory failure and centrilobular cellular damage [9]. This interaction can account for the observed increase in serum LDH activity because LDH is found in substantial amounts in both liver and RBC's, i.e. hepatic action of assaulting sporozoites leading to liver damage and the damage of host RBC. There is an essential consequence of this finding because it shows the potential of using serum LDH activity as a guide in observing plasmodium malaria infection, especially when all other potential causes of elevated serum LDH levels have been rejected.

The observed increase in ACP activity also supports the previous reports [10], which is due to host RBC hemolysis. Thus raise in serum ACP levels in patients with malaria could serve as an indicator for hemolysis signifying the active stage of the disease, and can be used as an investigation for the diagnosis of malaria.

\section{CONCLUSION}

The present study provides details and relationship concerning hepatic derangement and biochemical parameters in patients with vivax and falciparum malaria. Though malaria is diagnosed by the 
microscopic finding of the forms of malarial parasite occasionally parasite is not found even in severe infection, this may be clarified by incomplete treatment of malaria or by the presence of the cells with the parasite in deeper tissue beds.

Similarly, as artifacts are common during the interpretation of blood smear, it requires some experience. In such cases, ancillary evidences such as serum enzyme levels can have a definitive role and can be used precisely for the malaria diagnosis, mainly when other causes of raised enzyme levels are disregarded.

Early treatment with antimalarial drugs can be initiated based on these findings to prevent complications and to reduce mortality. These enzymatic indicators also have a supportive role as these can be performed along with other routine tests for the malaria diagnosis, to know the degree of hemolysis and liver damage and consequently the severity of the disease.

Finally, it can be concluded that the Role of Enzymatic Markers in the Diagnosis of Malaria is both Definitive and Supportive and hence, can be used comprehensively in the clinical scenario.

\section{REFERENCES}

1. World health organization. A global strategy for malaria control. Geneva. 1998.
2. White NJ, Ho M. the pathophysiology of malaria. Adv parasitol. 1992; 31:83-173.

3. Maegraith B. Aspects of the pathogenesis of malaria. Southeast Asian trop med pub health. 1981; 12:251-67.

4. Giboney PT. Mildly elevated liver transaminase levels in the asymptomatic patient. Am FAM Physician. 2005 Mar 15;71(6):1105-0.

5. Nnodim, Nwanjo HU and Opera. blood glucose level and liver enzyme activities in malarial patients in owerri. Journal of medical laboratory science. 2010;1(1)7-9.

6. Anderson HR, Nielsen JB, Philippe G. antioxidative enzyme activities in human erythrocytes. Clin Chem. 1997;43(4):562-8.

7. Gupta CM. Red cell membrane alterations in malaria. Ind J Biochem Biophys. 1988;25:20-4.

8. Guthrow CE, Morris JF, Day JW. Enhanced non-enzymatic glycosylation of human serum albumin. Quart. T. Med. 2007:30-8.

9. Maegraitrh B. Aspects of the pathgenesis of malaria.

10. Garba, Gatsing D, Uborn G. elevated total and isoenzyme forms of acid phosphatase in falciparum malaria. Comput Rendus Biol. 2006;329(2):75-8.

11. Noppadon T, Chatnapa D, Polrat W, Srivicha K. Malaria diagnosis: A brief review. Korean Journal of Parasitology. 2009;47(2):93-102.

12. Stryer L. Biochemistry Newyork: WH Freeman, 1982. 